(C) 2017. This manuscript version is made available under the CC-BY-NC-ND 4.0 license http://creativecommons.org/licenses/by-nc-nd/4.0/

DOI: 10.1016/j.jdiacomp.2017.06.016 


\section{Comparison of MDRD, CKD-EPI, and Cockcroft-Gault equation in relation to measured glomerular filtration rate among a large cohort with diabetes}

Anke Schwandta ${ }^{a, b}$, Michael Denkinger ${ }^{c}$, Peter Fasching ${ }^{d}$, Martin Pfeifer ${ }^{\mathrm{e}}$, Christian Wagner ${ }^{\mathrm{f}}$, Jörg Weiland $^{\mathrm{g}}$, Andrej Zeyfang ${ }^{\mathrm{h}}$, Reinhard W. Holl ${ }^{\mathrm{a}, \mathrm{b}}$

anstitute of Epidemiology and Medical Biometry, ZIBMT, University of Ulm, 89081 Ulm, Germany bGerman Center for Diabetes Research (DZD), 85764 Munich-Neuherberg, Germany

${ }^{\circ}$ Geriatric Center Ulm/Alb-Donau, Geriatric Medicine at Ulm University, Agaplesion Bethesda Hospital UIm, 89081 Ulm, Germany

d5th Medical Department, Wilhelminenspital, 1116 Vienna, Austria

eDiabetes Center, Clinic Tettnang, 88069 Tettnang, Germany.

fOutpatient Diabetes Center, 83416 Surheim, Germany

9Department of Internal Medicine, Hospital Bad Reichenhall, 83435 Bad Reichenhall, Germany

hSana Hospital Bethesda Stuttgart, 70184 Stuttgart, Germany

Corresponding author:

Anke Schwandt, M.Sc. mathematical Biometry

University of Ulm, Institute of Epidemiology and Medical Biometry, ZIBMT

Albert-Einstein-Allee 41, 89081 Ulm, Germany

E-Mail: anke.schwandt@uni-ulm.de

Part of the work was presented in the oral session of the annual meeting of the German Diabetes Association (DDG) which took place in Hamburg, Germany, 24-27th May 2017.

Keywords: Diabetes type 1; Diabetes type 2; glomerular filtration rate (GFR) 


\section{Abstract}

Aims: To analyze the performance of Modification of Diet in Renal Disease (MDRD), Chronic Kidney Disease Epidemiology Collaboration (CKD-EPI), Cockcroft-Gault (CG), and CG calculated with ideal bodyweight (CG-IBW) equations to estimate glomerular filtration rate (eGFR) based on serum creatinine in a large diabetic population.

Methods: 24,516 adults with type-1-diabetes or type-2-diabetes from the multicenter diabetes prospective follow-up registry DPV were analyzed. We compared eGFR and measured GFR (mGFR) based on 24-h urine collection by calculating mean bias (difference), precision (SD of this difference), accuracy (proportion of eGFR within $\pm 10 \%$ of $\mathrm{mGFR}$ ), Bland-Altman-plots.

Results: CG overestimates, whereas MDRD, CKD-EPI, and CG-IBW underestimate. Smallest mean bias and highest accuracy (75.3\%) were observed for MDRD compared to the other equations ( $p<0.0001)$. MDRD and CKD-EPI estimated most accurately in stages 1 (MDRD:57.7\%, CKD-EPI:57.3\%) and 2 (MDRD:80.2\%, CKD-EPI:80.7\%). In stages 3 to 5, highest accuracy was observed for the MDRD (stage3:82.3\%, stage4:77.8\%, stage5:71.0\%). Among younger subjects, accuracy was higher using the CKD-EPI (18-<40 years:63.7\%, 40-<60 years:72.8\%). Above age 60 years, MDRD estimated most accurately (60-<70 years:77.3\%, $\geq 70$ years:78.8\%). In males and females, MDRD estimated most accurately (males:75.3\%, females:75.3\%).

Conclusion: In this large diabetic cohort, smallest bias and highest accuracy were observed for the MDRD.

Words: 199 


\section{Introduction}

Chronic kidney disease (CKD) is a worldwide public health problem with increasing prevalence (1). CKD describes heterogeneous disorders affecting the structure and function of the kidney (1). Impaired renal function is a risk factor for cardiovascular disease and all-cause mortality (2). Kidney disease is associated with diabetes, older age, hypertension, obesity as well as genetic factors $(1,2)$. Overall, the leading cause of CKD is diabetes (3). Compared to the general population, the risk for impaired kidney function is higher in individuals with diabetes (2). The prevalence of nephropathy is $30 \%$ in subjects affected by type 1 diabetes (T1D) and 10 to $40 \%$ in individuals with type 2 diabetes (T2D) (4).

A degree of kidney failure is quantitated by the glomerular filtration rate (GFR) (5-7). The GFR is considered as the best overall indicator for renal function (6). However, depending on the method, measuring renal function is either expensive or time consuming and the reliability may depend on the accuracy of urine collection, particularly in older individuals (6). Therefore, several equations for estimating renal function based on serum creatinine have been developed. The commonly used formulas are Modification of Diet in Renal Disease (MDRD), Chronic Kidney Disease Epidemiology Collaboration (CKD-EPI), and Cockcroft-Gault (CG) (8-10). These equations have been discussed controversially. Currently, the MDRD is most frequently used by clinical laboratories (11). However, this formula might underestimate GFR in patients with normal to high creatinine levels (6). By analyzing subjects with a wide range of renal function, the CKD-EPI group suggested an equation applying different coefficients to the same parameters used in the MDRD formula $(7,12)$. Due to the limited clinical information in the original study, the validity of the CKDEPI could be limited for several subgroups $(13,14)$. The CG overestimates renal function and estimates are less accurate (13). However, a previous study demonstrated that in a small geriatric cohort, the CG calculated with ideal body weight (IBW) performed better than the CG with actual bodyweight (15).

Routine monitoring of renal function is mandatory in diabetes care $(13,16)$. Estimation of GFR is central to the diagnosis, evaluation, and management of kidney disease. In patients with diabetes the choice of medical treatment such as oral antidiabetics might be limited by renal function. The prevalence of impaired kidney function increases with age (17), highlighting the need for regular controls in older individuals. Hence, an accurate estimation is important, and improved accuracy has important implications for clinical practice and public health.

The performance of these equations has been rarely examined in large populations with diabetes. Thus, the aim of this study was to assess the agreement between measured and estimated renal function using the MDRD, CKD-EPI, CG, and CG-IBW equations among a large number of adult 
patients with diabetes from the German/Austrian DPV registry. Moreover, we analyzed the performance within stages of CKD, among age groups, as well as in males and females.

\section{Subjects, Materials and Methods}

\subsection{Data source and subjects}

The patients included in the current study were identified from the Diabetes-PatientenVerlaufsdokumentation (DPV), a multicenter diabetes follow-up registry. For 20 years, more than 400 specialized health care facilities from Germany, Austria, and Luxembourg use the prospective, standardized documentation system of diabetes care and outcome. Anonymized data are collected locally and transmitted semiannually to UIm, Germany. In case of implausibility or inconsistency, data are reported back to the centers for correction/verification. Data are aggregated into a cumulative database for clinical research and quality assurance. The Ethics Committee of the University of Ulm has authorized the DPV initiative as well as analyses of anonymized data related to quality of care. The local review board of each participating center has approved the collection of anonymized data (18).

Until September 2016, 453,380 patients were registered in DPV. Adult subjects ( $\geq 18$ years of age) with T1D or T2D were included. Patients without documentation of measured GFR (mGFR) based on 24-h urine creatinine excretion or parameters required to calculate the estimated GFR (eGFR) were excluded. A further exclusion criterion was renal dialysis. The final study population comprised 24,516 patients with diabetes from 138 centers (Figure 1). For each patient, the last year of treatment was analyzed.

\subsection{Outcomes}

Demographic data (sex, age, duration of diabetes) and clinical data (hemoglobin A1c (HbA1c), body mass index (BMI), body surface area (BSA), hypertension (systolic blood pressure $\geq 140$ $\mathrm{mmHg}$ /diastolic blood pressure $\geq 90 \mathrm{mmHg}$ or the use of antihypertensive drugs), microalbuminuria (urinary albumin excretion $>30 \mathrm{mg} / \mathrm{g}$ creatinine), treatment with ACE inhibitors, smoking) were analyzed. HbA1c was mathematically standardized to the Diabetes Control and Complications Trial (DCCT) reference range (20.7-42.6 $\mathrm{mmol} / \mathrm{mol})$ by applying the multiple-of-themean transformation method (19). BMI was calculated as $\mathrm{kg} / \mathrm{m}^{2}$. BSA were estimated using the formula of DeBois and DeBois (20).

Stages for chronic kidney disease (CKD) were defined according to the National Kidney Foundation Disease Outcomes Quality Initiative (NKF KDOQI) guidelines: $\geq 90,60-<90,30-<60$, 
$15-<30$, and $<15 \mathrm{ml} / \mathrm{min} / 1.73 \mathrm{~m}^{2}$ (21). 24-hour urine collection was used to determine creatinine clearance $\left(\mathrm{ml} / \mathrm{min} / 1.73 \mathrm{~m}^{2}\right)$. Serum creatinine was expressed as both $\mu \mathrm{mol} / \mathrm{l}$ and $\mathrm{mg} / \mathrm{dl}$.

The MDRD ( $\left.\mathrm{ml} / \mathrm{min} / 1.73 \mathrm{~m}^{2}\right)$ (9), CKD-EPI $\left(\mathrm{ml} / \mathrm{min} / 1.73 \mathrm{~m}^{2}\right)$ (10), CG (ml/min) (8), and CG calculated with IBW (ml/min) (15) equations were used to determine eGFR. Definition of estimation methods are shown in Table 1.

Both the MDRD and CKD-EPI include a term for the African American race. Since the proportion of black population is less than $2 \%$ in Germany (22) and no data on race was available, the term was excluded. In many studies, the CG equation was adjusted to estimated BSA. However, a recent article reported that formulas used to estimate BSA should be used carefully, particularly in patients with overweight (23). Due to the high BMI observed in the current cohort, the estimates of BSA might be conflicting. Therefore, the CG equation was not adjusted for BSA.

\subsection{Statistical analysis}

Results of descriptive statistics are presented as median with quartiles for continuous variables and as proportion for binary variables. To examine the correlation between measured and estimated GFR, spearman correlation coefficient was used.

Performance of each eGFR equation was assessed in terms of bias, precision, and accuracy. Bias was defined as the mean difference between measured and estimated GFR, and the standard deviation (SD) of this difference was defined as precision. Accuracy was expressed as the proportion of eGFR results within $\pm 10 \%$ of $\mathrm{mGFR}$ values. Bias, precision, and accuracy were also evaluated separately for stages of CKD, age groups $(18-<40,40-<60,60-<70$, and $\geq 70$ years), and gender. Additionally, BMl groups (normal weight $\mathrm{BMl}<25$, overweight $25 \leq \mathrm{BMl}<30$, obese $B M I \geq 30$ ) were examined. Comparing the differences in bias and accuracy between the formulas, paired t-test and McNemar test were used. To investigate the agreement between the measured and estimated GFR, Bland-Altman-plots were performed (24). The difference between mGFR and eGFR is plotted against the mean of mGFR and eGFR. Bias and the 95\% limits of agreement which were calculated as the mean difference \pm 1.96 times the precision were examined. Agreement between mGFR and eGFR in their classification into CKD stages was analyzed by Cohen's $\kappa$.

Statistical Analysis Software 9.4 (SAS Institute Inc., Cary, NC, USA) was used for all analyses. Due to the large number of subjects, a two-sided $p$-value $<0.01$ was considered significant.

\section{Results}


In the current study, 22,294 subjects with T2D and 2,222 individuals with T1D were analyzed. Demographics of the entire study cohort as well as stratified by type of diabetes are described in Table 2.

\subsection{Comparing the MDRD, CKD-EPI, CG, and CG-IBW equations}

Strong correlation between mGFR and eGFR was observed for all formulas, with $r_{M D R D}=0.95, r_{C K D}$ ${ }_{E P I}=0.95, r_{C G}=0.85$, and $r_{C G-I B W}=0.90$.

Figure 2 depicts Bland-Altman plots of the measured and estimated renal function with bias and $95 \%$ limits of agreement for each equation. The CG overestimates, whereas the MDRD, CKDEPI, and CG-IBW underestimate GFR. Smallest mean bias was observed for the MDRD compared to the CKD-EPI, CG, and CG-IBW equations ( $p<0.0001)$.

The MDRD estimated measured GFR (based on 24-h urine creatinine) most accurately $(75.3 \%$ of patients with less than $10 \%$ difference between mGFR and eGFR, $p<0.0001)$. Accuracy was $70.4 \%$ for the CKD-EPI, $27.2 \%$ for the CG, and $30.5 \%$ for the CG-IBW.

Analyzing individuals with T1D and T2D separately, similar findings were observed among subjects with T2D; however, in individuals with T1D, performance of the CKD-EPI was better compared to the other equations.

\subsection{Stratification by stages of kidney disease}

Figure 3A depicts mean bias and precision stratified by stages of CKD. Larger mean bias was associated with higher GFR for all equations. Comparing all estimation methods, smallest mean bias was observed for the MDRD in the normal kidney function group (GFR $\geq 90 \mathrm{ml} / \mathrm{min} / 1.73 \mathrm{~m}^{2}$, $\mathrm{p}<0.0001$ ). In CKD stage 2 (GFR $60-<90 \mathrm{ml} / \mathrm{min} / 1.73 \mathrm{~m}^{2}$ ) a less biased estimate was found for the CKD-EPI ( $p<0.0001)$. Among patients in CKD stage 3 (GFR $30-<60 \mathrm{ml} / \mathrm{min} / 1.73 \mathrm{~m}^{2}$ ), the MDRD equation estimated least biased $(p<0.0001)$. In patients with severely reduced kidney function (GFR $15-<30 \mathrm{ml} / \mathrm{min} / 1.73 \mathrm{~m}^{2}$ ) or endstage kidney function (GFR $<15 \mathrm{ml} / \mathrm{min} / 1.73 \mathrm{~m}^{2}$ ), smallest mean bias was observed for the CKD-EPI (both $p<0.0001$ ).

Table 3 shows accuracy stratified by stages of kidney function for each estimation method. In CKD stage 1 and 2, highest accuracy was observed for the MDRD and CKD-EPI compared to the CG and CG-IBW equations ( $p<0.0001$ ), while in stages 3 to 5 MDRD estimates renal function most accurately (all $p<0.0001$ ).

Among patients with renal hyperfiltration (GFR $\geq 160 \mathrm{ml} / \mathrm{min} / 1.73 \mathrm{~m}^{2}$ ), correlation between measured and estimated renal function was low, with $r_{\mathrm{MDRD}}=0.29, r_{\mathrm{CKD}-\mathrm{EPI}}=0.35, r_{\mathrm{CG}}=0.26$, and $r_{\mathrm{CG}}$ $\mathrm{IBW}=0.27$. 
Classification of patients according to measured or estimated renal function into stages of CKD were investigated. The CKD-EPI and MDRD classified most patients correctly into stages of kidney disease $\left(\kappa_{\mathrm{CKD}-\mathrm{EPI}}=0.77, \kappa_{\mathrm{MDRD}}=0.74\right)$ compared to the $\mathrm{CG}$ and $\mathrm{CG}-\mathrm{IBW}$ equations $\left(\kappa_{C G}=0.49, \kappa_{C G-1 B W}=0.49\right)$.

\subsection{Stratification by age groups}

Mean bias and precision for age groups are shown in Figure 3B. With increasing age, performance of estimates was better for all equations. Comparing all estimation methods, mean bias was smallest for the CKD-EPI in the youngest age group $(18-<40$ years, $p<0.0001)$. Among patients aged $40-<60$ years, the CG-IBW estimated renal function less biased $(p<0.0001)$. In the $60-<70$ year olds, MDRD and CKD-EPI provided less biased estimates (both $p<0.0001$ ). In the oldest age group ( $\geq 70$ years), smallest mean bias was found for $C G(p<0.0001)$.

Accuracy stratified by age group is depicted in Table 3 for all formulas. The CKD-EPI estimated renal function most accurately in the younger individuals ( $<60$ years), whereas in subjects aged $\geq 60$ years, estimates were most accurate using MDRD (both $p<0.0001$ ).

\subsection{Stratification by gender}

Figure $3 \mathrm{C}$ depicts mean bias and precision separately for males and females. Comparing all equations, smallest mean bias was observed using the MDRD in males $(p<0.0001)$, whereas in females the CKD-EPI performed a less biased estimate $(p<0.0001)$.

For both males and females, the MDRD estimated GFR values most accurately compared to CKDEPI, CG, and CG-IBW equations (Table 3, both $p<0.0001$ ).

\subsection{Stratification by $B M I$ groups}

In the normal weight $(B M I<25)$, overweight $(25 \leq B M I<30)$, and obese $(B M I \geq 30)$ group, the MDRD and CKD-EPI provided smaller mean bias compared to the CG and CG-IBW equations $(p<0.0001$, see Supplement Figure 1). With increasing BMI, larger mean bias was observed for the CG equation. Highest accuracy was observed for the MDRD in the normal weight, overweight, and obese group compared to the other formulas (Table $3, p<0.0001$ ).

\subsection{Subanalysis}

\section{Stratification by hypertension}

Among patients with hypertension, the MDRD provided smaller mean bias compared to the other formulas (all $p<0.0001$ ), whereas in individuals without hypertension smaller mean bias was observed for the CKD-EPI (all $p<0.0001$ ). Highest accuracy was found for the MDRD among 
subject with and without hypertension compared to the CKD-EPI, CG, and CG-IBW (Table 3, all $\mathrm{p}<0.0001)$.

\section{Stratification by microalbuminuria}

Mean bias was smallest for the MDRD equation among patients with microalbuminuria (all $\mathrm{p}<0.0001$ ), while in subjects without microalbuminuria both the MDRD and CKD-EPI estimated renal function less biased (all $p<0.0001$ ). Among individuals with and without microalbuminuria, estimates were most accurate using the MDRD equation compared to CKD-EPI, CG, and CGIBW (Table 3, all p<0.0001).

\section{Discussion}

The present multicenter study aimed to analyze the performance of the MDRD, CKD-EPI, CG, and CG-IBW equations to estimate renal function among a large German/Austrian cohort of adults with diabetes by comparing estimates to measured GFR based on 24-h urine creatinine excretion. The MDRD provided a least biased estimate together with the highest accuracy in the entire cohort. Moreover, we examined performance within subgroups. In patients with normal and mildly reduced kidney function (GFR $\geq 60 \mathrm{ml} / \mathrm{min} / 1.73 \mathrm{~m}^{2}$ ), high accuracy was observed for MDRD and CKD-EPI. In patients with impaired renal function (GFR $<60 \mathrm{ml} / \mathrm{min} / 1.73 \mathrm{~m}^{2}$ ), estimates were most accurate using MDRD. In younger individuals ( $<60$ years), the CKD-EPI estimated more accurately, while in subjects aged $\geq 60$ years, highest accuracy was found for the MDRD. MDRD estimated renal function most accurately in males and females.

Differences in performance of the MDRD, CKD-EPI, CG, and CG-IBW equations in a large diabetic cohort have not been compared before. Both the CKD-EPI and MDRD underestimate GFR in the general population as well as in patients with diabetes (25), whereas the CG overestimates renal function (26). Rognant et al. (27) confirmed our finding of smallest bias as well as highest accuracy for the MDRD in a diabetic population. Even though many studies concluded that in the general population CKD-EPI is more accurate than MDRD, it is not known whether the CKD-EPI can be applied across various populations such as in elderly or individuals with impaired renal function $(6,7)$. The performance depends on the cohort examined (26). In subjects with diabetes, results are contradictory. Whereas in some previous studies the CKD-EPI did not perform better than the $\operatorname{MDRD}(6,12,25,27)$, other studies reported that the CKD-EPI is slightly more precise in predicting kidney function $(5,10,13)$. Further reports stated that the CKD-EPI might not work equally well in subjects with a high risk of cardiovascular disease (5) or diabetes (25). It is well established that the MDRD provides more accurate estimates for GFR below $60 \mathrm{ml} / \mathrm{min} / 1.73 \mathrm{~m}^{2}$. Therefore, an 
explanation for the higher accuracy using the MDRD in the current study cohort might be the high frequency of subjects $(47 \%)$ with impaired renal function.

Studies concluded that the CG equation should not be used in individuals with diabetes $(27,28)$. The formula provides poor estimates and overestimates kidney function $(27,29)$. A reason might be that the CG calculates creatinine clearance proportional to bodyweight $(30,31)$. Especially in patients with T2D, bodyweight might be an important cause for poor performance due to the high frequency of overweight and obesity (29). The use of IBW instead of actual bodyweight may correct this bias; however, using the CG-IBW, underestimation of renal function was observed (28). A recent Dutch study compared in a small geriatric cohort the commonly used equations with a gold standard (sinistrin clearance) (15). The authors indicated that the CG-IBW provides better estimates. Furthermore, a study reported previously that the CG might be a good alternative in elderly patients or in those with low bodyweight (32). Conflicting results might be explained by heterogeneous study populations, different sample size, adjustment for BSA, or diverse reference methods used to determine mGFR.

All equations display worse performance at normal renal function due to greater biologic and measurement variability at higher GFR $(32,33)$. Further reasons for the wide variation among normal and high GFR values might be inter-laboratory variation which has larger effects at higher GFR values, differences of creatinine excretion among and within individuals, influence of drugs on creatinine clearance as well as muscle mass and dietary intake determining the generation of creatinine (34). Particularly in individuals with diabetes, CKD-EPI and MDRD significantly underestimate renal function at higher GFR $(25,35)$. While in most studies the equations were compared between patients with and without CKD (27), only few studies have examined the performance stratified by stage of CKD $(32,36)$. In a previous research the performance among stages of CKD was similar for the MDRD and CKD-EPI (32). However, Rognat et al. (27) revealed that the MDRD equation exhibited the highest accuracy in a diabetic population with and without CKD. In our study, highest accuracy was observed for the CKD-EPI and MDRD in subjects with normal and mildly reduced kidney function; however, in individuals with impaired renal function, highest accuracy was found for MDRD.

Due to similar creatinine levels, but higher GFR values in younger than in older individuals, all methods include a term for age (33). With increasing age, improved estimates of renal function were found $(32,36)$. Previous studies demonstrated that the MDRD is less accurate in younger subjects with diabetes (2). A study conducted by Stevens et al. (37) corroborated our finding of better estimates using the CKD-EPI in younger individuals ( $<60$ years) compared to the MDRD. 
However, findings from other studies indicated that the MDRD predicted GFR more accurately in older subjects $(17,38)$. This is in line with our finding of more precise estimates by the MDRD in older individuals ( $\geq 60$ years). A reason for these findings might be higher GFR values in younger subjects and lower GFR in the elderly.

To account for higher GFR in males compared to females at the same serum creatinine level, a term for female sex is included in all equations (33). Irrespective of gender, accuracy was highest for the MDRD compared to the CKD-EPI, CG, and CG-IBW. White et al. (14) reported previously that the CKD-EPI equation provides a better estimate of CKD in females than in males. This confirms our finding that the CKD-EPI was less biased in females, whereas in males the MDRD provided smallest bias.

Whereas most studies examined a diabetic cohort (6) or either individuals with T1D or T2D $(5,13)$, a recent study exhibited that the MDRD provided highest accuracy for both subjects with T1D and T2D (27). We observed similar findings in individuals with T2D; however, among subjects with T1D, performance of CKD-EPI was better compared to the other equations. Different findings might be due to age differences, diverse sample size or heterogeneous ranges of kidney function.

The relation between $\mathrm{BMI}$ and performance of estimation methods was investigated in a previous cross-sectional study (32). The authors demonstrated that using the CG equation the estimation of renal function depends on BMI contrary to the MDRD and CKD-EPI. With increasing BMI, larger bias was observed for the CG formula. Moreover, in our diabetic cohort, highest accuracy was found for the MDRD in the normal weight, overweight, and obese group.

Previous reports demonstrated limitations of generalizing an equation developed in one population to another population (33). The disappointing performance in subjects with diabetes can be partially attributed to the relationship between age, metabolic control, and renal function (25). Compared to the general population, hyperglycemia, glomerular hyperfiltration, higher BMI as well as higher creatinine levels despite similar GFR might be related to the algorithms in a diabetic population (25,35). Another reason might be the influence of medical treatment such as antidiabetic drugs on creatinine levels $(12,39,40)$. New equations based on serum cystatin $C$ have been developed. The ActiFE Study group investigated the prevalence of CKD estimated by the MDRD, CKD-EPI, and Cystatin $C$ based equation. The authors demonstrated that the prevalence of CKD varied between $14.6 \%$ for the Cystatin $C$ based equation to $33.0 \%$ and $34.3 \%$ for the CKDEPI and MDRD (41). However, recently in a cross-sectional study, methods based on cystatin C 
did not provide better estimates than creatinine based formulas (13). Therefore, further research is necessary to develop more precise tools to estimate GFR in individuals with diabetes.

We acknowledge some limitations of our study. Due to the multicenter structure of this study, renal function and serum creatinine were not measured centrally, and therefore differences cannot be excluded completely. The use of 24-hour urine collection to measure creatinine clearance has some limitations. Previous studies reported that this method is not considered precise enough to be used in assessment of renal function $(42,43)$. Reliability of 24-hour urine collection may depend on completeness of urine sampling, especially in older age groups, and also on variation in creatinine excretion. We could not compare renal function determined by cystatin $\mathrm{C}$ methods or radionuclide clearance with results of eGFR, as cystatin C methods are expensive as well as radionuclide clearance is expensive and cumbersome, and therefore not suitable for daily practice. Since the current study cohort comprised German/Austrian subjects with diabetes, our results might not be generalizable to other populations, such as individuals without diabetes or other ethnic groups.

A strength of this study is the huge number of adult subjects with T1D or T2D, as we are able to compare the commonly used equations based on serum creatinine to estimate the kidney function in a large diabetic population. The DPV database provides detailed information on characteristics of the study population that allow to analyze the influence of CKD stages, age, and gender on the performance of estimation methods.

In conclusion, the MDRD equation provides a clinically useful estimate of renal function among adults with diabetes as well as in most subgroups. However, further estimation methods or the use of biomarkers instead of serum creatinine might lead to more accurate estimates of kidney function.

\section{Acknowledgements}

The authors thank all participating centers of the DPV initiative, especially the collaborating centers in this investigation: Rosenheim Innere Medizin, Dortmund Knappschaftskrankenhaus Innere, Bad Aibling Internist. Praxis, Rosenheim Schwerpunktpraxis, Bad Reichenhall Kreisklinik Innere Med., Saaldorf-Surheim Diabetespraxis, Prenzlau Krankenhaus Innere, Berlin Parkklinik Weissensee, Neuwied Marienhaus Klinikum St. Elisabeth Innere, Plauen Vogtlandklinikum, Bremen - Mitte Innere, Berlin Evang. Krankenhaus Königin Elisabeth, Dortmund-St. Josefshospital Innere, Dortmund-Hombruch Marienhospital, Traunstein diabetol. Schwerpunktpraxis, Krefeld-Uerdingen St. Josef Innere, Tettnang Innere Medizin, Wangen 
Oberschwabenklinik Innere Medizin, Darmstadt Innere Medizin, Iserlohn Innere Medizin, Oschersleben MEDIGREIF Bördekrankenhaus, Kleve Innere Medizin, Coburg Innere Medizin, Wernberg-Köblitz SPP, Trostberg Innere, Landau Innere, Friedberg Innere Klinik, Magdeburg Städtisches Klinikum Innere, Eisleben Lutherstadt Helios-Klinik, Timmendorfer Strand, Krefeld Innere Klinik, Münster Herz Jesu Innere, Forchheim Diabeteszentrum SPP, Güstrow Innere, Berlin DRK-Kliniken Westend Innere, Frankfurt-Sachsenhausen Innere, Duisburg Malteser St. Johannes, Rodalben St. Elisabeth, Nürnberg Med. Klinik 4, Duisburg Malteser Rhein-Ruhr St. Anna Innere, Heilbronn Innere Klinik, Limburg Innere Medizin, Frankfurt Uni-Klinik Innere, Freiburg Uni Innere, Coesfeld/Dülmen Innere Med., Geislingen Klinik Helfenstein Innere, Reutlingen Klinikum Steinenberg Innere, Magdeburg Uni-Kinderklinik, Berlin Virchow-Kinderklinik, Eberswalde Klinikum Barnim Werner Forßmann - Innere, Herne Evan. Krankenhaus Innere, Kaiserslautern-Westpfalzklinikum Kinderklinik, Pfullendorf Innere Medizin, Krefeld Kinderklinik, Lünen Klinik am Park, Heidelberg Uni-Kinderklinik, Kamen Klinikum Westfalen Hellmig Krankenhaus, Villingen-Schwenningen Schwarzwald-Baar-Klinikum Innere, Lilienthal Diabeteszentrum, Herford Innere Med I, Altötting-Burghausen Innere Medizin, Frankfurt Uni-Klinik Innere, Gelnhausen Innere, Lübeck Uni-Klinik Innere Medizin, Oberndorf Gastroenterologische Praxis Schwerpunkt Diabetologie, Konstanz Innere Klinik, Frankfurt-Sachsenhausen Innere MVZ, Ulm Uni-Kinderklinik, Wiesbaden Kinderklinik DKD, Spaichingen Innere, Asbach Kamillus-Klinik Innere, Berlin Vivantes Hellersdorf Innere, Weisswasser Kreiskrankenhaus, Halberstadt Innere Med. AMEOS Klinik, Berlin Schlosspark-Klinik Innere, Berchtesgaden MVZ Innere Med, Wien Wilhelminenspital 5. Med. Abteilung, Augsburg IV. Med. Klinik, Berlin Klinik St. Hedwig Innere, Frankfurt Uni-Kinderklinik, Nürnberg Cnopfsche Kinderklinik, Wolgast Innere Medizin, DortmundWest Innere, Bottrop Knappschaftskrankenhaus Innere, Gelsenkirchen Kinderklinik Marienhospital, München Diabetes-Zentrum Süd, Berlin Oskar Zieten Krankenhaus Innere, Pirmasens Städtisches Krankenhaus Innere, Ingolstadt Klinikum Innere, Bayreuth Innere Medizin, Ottobeuren Kreiskrankenhaus, Ulm Uni Innere Medizin, Neumarkt Innere, Duisburg-St.Johannes Helios, Jena diabetol. Schwerpunktpraxis, Wien Uni-Kinderklinik, Deggendorf Medizinische Klinik II, Mannheim Uniklinik Innere Medizin, Rastatt Kreiskrankenhaus Innere, Stuttgart Olgahospital Kinderklinik, Chemnitz-Hartmannsdorf Innere Medizin - DIAKOMED-1, Kirchen DRK Krankenhaus Kinderklinik, Berchtesgaden CJD, Göppingen Innere Medizin, Osterkappeln Innere, Dortmund Medizinische Kliniken Nord, Kaiserslautern Kinderarztpraxis, Berlin Lichtenberg - Kinderklinik, Halle Uni-Kinderklinik, Hamburg-Nord Kinder-MVZ, Itzehoe Kinderklinik, Kempen Heilig Geist Innere, Lüdenscheid Märkische Kliniken - Kinder \& Jugendmedizin, Marburg Uni-Kinderklinik, Mönchengladbach Kinderklinik Rheydt Elisabethkrankenhaus, Idar Oberstein Innere, Bad Lauterberg Diabeteszentrum Innere, Herten St. Elisabeth Innere Medizin, Heringsdorf Inselklinik, 
Nidda Bad Salzhausen Klinik Rabenstein/Innere-1 Reha, Fulda Innere Medizin, München-Gauting Kinderarztzentrum, Köln Kinderklinik Amsterdamerstrasse, Reutlingen Kinderarztpraxis, Linz Krankenhaus Barmherzige Schwestern Kardiologie Abt. Int. II, Aachen - Innere RWTH, Neunkirchen Innere Medizin, Schwäbisch Hall Diakonie Innere Medizin, Wittenberg Innere Medizin, Stuttgart Bethesda Agaplesion, Wien 3. Med. Hietzing Innere, Murnau am Staffelsee diabetol. SPP, Innsbruck Universitätsklinik Innere, Castrop-Rauxel Rochus-Hospital, Linz AKH 2. Med, Duisburg-Huckingen Malteser Rhein-Ruhr ST. Johannes, Klagenfurt Innere Med I, Memmingen Internistische Praxis.

\section{Reference}

1. Levey AS, Coresh J: Chronic kidney disease. Lancet 379(9811): 165-180, 2012.

2. Coresh J, Astor BC, Greene T, Eknoyan G, Levey AS: Prevalence of chronic kidney disease and decreased kidney function in the adult US population: Third National Health and Nutrition Examination Survey. Am J Kidney Dis 41(1): 1-12, 2003.

3. Pyram R, Kansara A, Banerji MA, Loney-Hutchinson L: Chronic kidney disease and diabetes. Maturitas 71(2): 94-103, 2012.

4. National Kidney Foundation. Diabetes - a major risk factor for kidney disease. https://www.kidney.org/atoz/content/diabetes. Accessed April 2017.

5. Targher G, Zoppini G, Mantovani W, Chonchol M, Negri C, Stoico V, Mantovani A, De Santi F, Bonora E: Comparison of two creatinine-based estimating equations in predicting all-cause and cardiovascular mortality in patients with type 2 diabetes. Diabetes Care 35(11): 2347-2353, 2012.

6. Drion I, Joosten H, Groenier KH, Lieverse AG, Kleefstra N, Wetzels JF, Bilo HJ: Equations estimating renal function in patients with diabetes. Neth J Med 69(10): 455-460, 2011.

7. Matsushita K, Mahmoodi BK, Woodward M, Emberson JR, Jafar TH, Jee SH, Polkinghorne KR, Shankar A, Smith DH, Tonelli M, Warnock DG, Wen CP, Coresh J, Gansevoort RT, Hemmelgarn BR, Levey AS, Chronic Kidney Disease Prognosis Consortium: Comparison of risk prediction using the CKD-EPI equation and the MDRD study equation for estimated glomerular filtration rate. JAMA 307(18): 1941-1951, 2012.

8. Schmechel H, Fünfstück R, Folger U, Robiller F, Schmechel R: clinical remarks on the estimation of the glomerular filtration rate (GFR) by the Cockroft-Galut equation - a trial to correct it. Nieren Hochdruckkrankh 34(10): 433-44, 2005.

9. Levey AS, Bosch JP, Lewis JB, Greene T, Rogers N, Roth D: A more accurate method to estimate glomerular filtration rate from serum creatinine: a new prediction equation. Modification of Diet in Renal Disease Study Group. Ann Intern Med 130(6): 461-470, 1999. 
10. Levey AS, Stevens LA, Schmid CH, Zhang YL, Castro AF,3rd, Feldman HI, Kusek JW, Eggers P, Van Lente F, Greene T, Coresh J, CKD-EPI (Chronic Kidney Disease Epidemiology Collaboration): A new equation to estimate glomerular filtration rate. Ann Intern Med 150(9): 604612, 2009.

11. The Collage of American Pathologists. Current status of reporting estimated glomerular filtration rate (eGFR). http://www.cap.org/apps/docs/committees/chemistry/current-statusreporting-egfr-2013.pdf. Accessed November 2016.

12. Camargo EG, Soares AA, Detanico AB, Weinert LS, Veronese FV, Gomes EC, Silveiro SP: The Chronic Kidney Disease Epidemiology Collaboration (CKD-EPI) equation is less accurate in patients with Type 2 diabetes when compared with healthy individuals. Diabet Med 28(1): 90-95, 2011.

13. Iliadis F, Didangelos T, Ntemka A, Makedou A, Moralidis E, Gotzamani-Psarakou A, Kouloukourgiotou T, Grekas D: Glomerular filtration rate estimation in patients with type 2 diabetes: creatinine- or cystatin C-based equations? Diabetologia 54(12): 2987-2994, 2011.

14. White SL, Polkinghorne KR, Atkins RC, Chadban SJ: Comparison of the prevalence and mortality risk of CKD in Australia using the CKD Epidemiology Collaboration (CKD-EPI) and Modification of Diet in Renal Disease (MDRD) Study GFR estimating equations: the AusDiab (Australian Diabetes, Obesity and Lifestyle) Study. Am J Kidney Dis 55(4): 660-670, 2010.

15. Drenth-van Maanen AC, Jansen PA, Proost JH, Egberts TC, van Zuilen AD, van der Stap D, van Marum RJ: Renal function assessment in older adults. Br J Clin Pharmacol 76(4): 616-623, 2013.

16. Molitch ME, DeFronzo RA, Franz MJ, Keane WF, Mogensen CE, Parving HH, Steffes MW, American Diabetes Association: Nephropathy in diabetes. Diabetes Care 27 Suppl 1: S79-83, 2004.

17. Willems JM, Vlasveld T, den Elzen WP, Westendorp RG, Rabelink TJ, de Craen AJ, Blauw GJ: Performance of Cockcroft-Gault, MDRD, and CKD-EPI in estimating prevalence of renal function and predicting survival in the oldest old. BMC Geriatr 13: 113-2318-13-113, 2013.

18. Bohn B, Kerner W, Seufert J, Kempe HP, Jehle PM, Best F, Fuchtenbusch M, Knauerhase A, Hofer M, Rosenbauer J, Holl RW, DPV-initiative: Trend of antihyperglycaemic therapy and glycaemic control in 184,864 adults with type 1 or 2 diabetes between 2002 and 2014: Analysis of real-life data from the DPV registry from Germany and Austria. Diabetes Res Clin Pract 115: 31-38, 2016.

19. Rosenbauer J, Dost A, Karges B, Hungele A, Stahl A, Bachle C, Gerstl EM, Kastendieck C, Hofer SE, Holl RW, DPV Initiative and the German BMBF Competence Network Diabetes Mellitus: Improved metabolic control in children and adolescents with type 1 diabetes: a trend analysis using prospective multicenter data from Germany and Austria. Diabetes Care 35(1): 8086, 2012.

20. DuBois D, DuBois E: A formula to estimate the approximate surface area if height and weight be known. Arch Intern Med 17: 863-71, 1916. 
21. National Kidney Foundation. K/DOQI clinical practice guidelines for chronic kidney disease: evaluation, classification, and stratification. Am J Kidney Dis 39(2 Suppl 1): S1-266, 2002.

22. Federal State Office. Number of foreigners in Germany by country of origin in 2014 and 2015. www.statista.com. Accessed February 2017.

23. Redlarski G, Palkowski A, Krawczuk M: Body surface area formulae: an alarming ambiguity. Sci Rep 6: 27966, 2016.

24. Bland JM, Altman DG: Statistical methods for assessing agreement between two methods of clinical measurement. Lancet 1(8476): 307-310, 1986.

25. Maclsaac RJ, Ekinci El, Premaratne E, Lu ZX, Seah JM, Li Y, Boston R, Ward GM, Jerums G: The Chronic Kidney Disease-Epidemiology Collaboration (CKD-EPI) equation does not improve the underestimation of Glomerular Filtration Rate (GFR) in people with diabetes and preserved renal function. BMC Nephrol 16: 198-015-0196-0, 2015.

26. Poggio ED, Wang X, Greene T, Van Lente F, Hall PM: Performance of the modification of diet in renal disease and Cockcroft-Gault equations in the estimation of GFR in health and in chronic kidney disease. J Am Soc Nephrol 16(2): 459-466, 2005.

27. Rognant N, Lemoine S, Laville M, Hadj-Aissa A, Dubourg L: Performance of the chronic kidney disease epidemiology collaboration equation to estimate glomerular filtration rate in diabetic patients. Diabetes Care 34(6): 1320-1322, 2011.

28. Rigalleau V, Lasseur C, Perlemoine C, Barthe N, Raffaitin C, Chauveau P, Combe C, Gin H: Cockcroft-Gault formula is biased by body weight in diabetic patients with renal impairment. Metabolism 55(1): 108-112, 2006.

29. Rigalleau V, Lasseur C, Perlemoine C, Barthe N, Raffaitin C, Liu C, Chauveau P, BailletBlanco L, Beauvieux MC, Combe C, Gin H: Estimation of glomerular filtration rate in diabetic subjects: Cockcroft formula or modification of Diet in Renal Disease study equation? Diabetes Care 28(4): 838-843, 2005.

30. van de Ree MA, Christiaan G, Huisman MV, van der Vijver JC, Meinders AE: Monitoring renal function in obese patients with type 2 diabetes mellitus in daily practice. Diabetes Nutr Metab 14(2): 66-70, 2001.

31. Rigalleau V, Beauvieux MC, Gonzalez C, Raffaitin C, Lasseur C, Combe C, Chauveau P, De la Faille R, Rigothier C, Barthe N, Gin H: Estimation of renal function in patients with diabetes. Diabetes Metab 37(5): 359-366, 2011.

32. Michels WM, Grootendorst DC, Verduijn M, Elliott EG, Dekker FW, Krediet RT: Performance of the Cockcroft-Gault, MDRD, and new CKD-EPI formulas in relation to GFR, age, and body size. Clin J Am Soc Nephrol 5(6): 1003-1009, 2010.

33. National Kidney Foundation. Frequently asked questions about GFR estimates. https://www.kidney.org/content/frequently-asked-questions-about-gfr-estimates. Accessed December 2016. 
34. Stevens LA, Coresh J, Greene T, Levey AS: Assessing kidney function--measured and estimated glomerular filtration rate. N Engl J Med 354(23): 2473-2483, 2006.

35. Silveiro SP, Araujo GN, Ferreira MN, Souza FD, Yamaguchi HM, Camargo EG: Chronic Kidney Disease Epidemiology Collaboration (CKD-EPI) equation pronouncedly underestimates glomerular filtration rate in type 2 diabetes. Diabetes Care 34(11): 2353-2355, 2011.

36. Carter JL, Stevens PE, Irving JE, Lamb EJ: Estimating glomerular filtration rate: comparison of the CKD-EPI and MDRD equations in a large UK cohort with particular emphasis on the effect of age. QJM 104(10): 839-847, 2011.

37. Stevens LA, Schmid CH, Greene T, Zhang YL, Beck GJ, Froissart M, Hamm LL, Lewis JB, Mauer M, Navis GJ, Steffes MW, Eggers PW, Coresh J, Levey AS: Comparative performance of the CKD Epidemiology Collaboration (CKD-EPI) and the Modification of Diet in Renal Disease (MDRD) Study equations for estimating GFR levels above $60 \mathrm{~mL} / \mathrm{min} / 1.73 \mathrm{~m} 2$. Am J Kidney Dis 56(3): 486-495, 2010.

38. Verhave JC, Fesler P, Ribstein J, du Cailar G, Mimran A: Estimation of renal function in subjects with normal serum creatinine levels: influence of age and body mass index. $\mathrm{Am} J$ Kidney Dis 46(2): 233-241, 2005.

39. Muller C, Dimitrov Y, Imhoff O, Richter S, Ott J, Krummel T, Bazin-Kara D, Chantrel F, Hannedouche T, CERRENE, CERRENE study group: Oral antidiabetics use among diabetic type 2 patients with chronic kidney disease. Do nephrologists take account of recommendations? J Diabetes Complications 30(4): 675-680, 2016.

40. Douros A, Ebert N, Jakob O, Martus P, Kreutz R, Schaeffner E: Estimating kidney function and use of oral antidiabetic drugs in elderly. Fundam Clin Pharmacol 29(3): 321-328, 2015.

41. Rothenbacher D, Klenk J, Denkinger M, Karakas M, Nikolaus T, Peter R, Koenig W, ActiFE Study Group: Prevalence and determinants of chronic kidney disease in community-dwelling elderly by various estimating equations. BMC Public Health 12: 343-2458-12-343, 2012.

42. Shemesh O, Golbetz H, Kriss JP, Myers BD: Limitations of creatinine as a filtration marker in glomerulopathic patients. Kidney Int 28(5): 830-838, 1985.

43. Proulx NL, Akbari A, Garg AX, Rostom A, Jaffey J, Clark HD: Measured creatinine clearance from timed urine collections substantially overestimates glomerular filtration rate in patients with liver cirrhosis: a systematic review and individual patient meta-analysis. Nephrol Dial Transplant 20(8): 1617-1622, 2005.

\section{Declaration of Interest}

The authors declare that they have no conflicts of interest relevant to this article.

Author Contributions 
Data analysis: AS and RWH. AS wrote/edited the manuscript. RWH is the principle investigator of the study, contributed to data analysis and interpretation, and reviewed/edited the manuscript. MD, PF, MP, CW, JW, and AZ researched data und reviewed/edited the manuscript. All co-authors approved the final version to be published.

\section{Funding}

The study was financially supported by the Federal Ministry of Education and Research within the German Competence Network for Diabetes mellitus (grant number: 01GI1106) which is integrated in the German Center for Diabetes Research (DZD) as of January 2015. This project has received funding from the Innovative Medicines Initiative 2 Joint Undertaking under grant agreement No 115797 (INNODIA) supported by from the Union's Horizon 2020 research and innovation program and "EFPIA", 'JDRF" and "The Leona M. and Harry B. Helmsley Charitable Trust". The German Diabetes Association (DDG) and the European Foundation for the Study of Diabetes (EFSD) provided further financial support. Sponsors were not involved in data acquisition or analysis. 


\section{Figures}

\section{Figure 1}

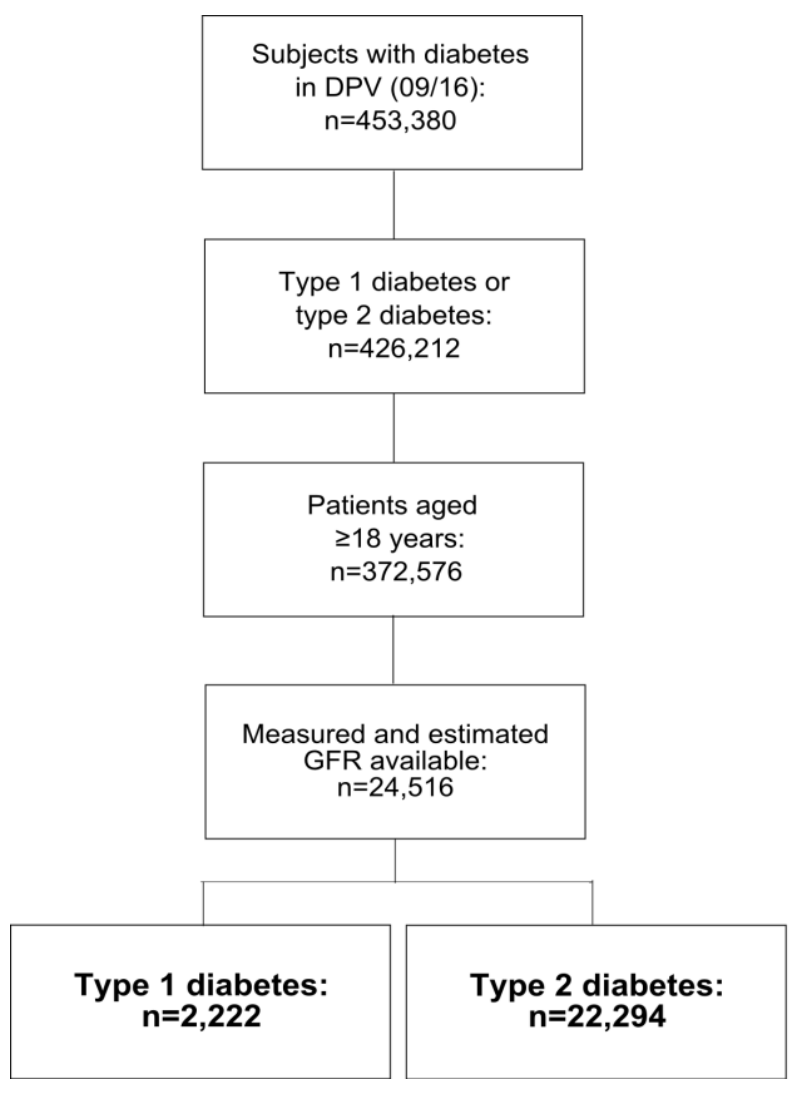

Figure depicts selection of the study cohort. Patients without documentation of measured GFR or parameters required to calculate the estimated GFR (eGFR) using the Modification of Diet in Renal Disease (MDRD), Chronic Kidney Disease Epidemiology Collaboration (CKD-EPI) or Cockcroft-Gault (CG) equations were excluded. A further exclusion criterion was renal dialysis. 
Figure 2
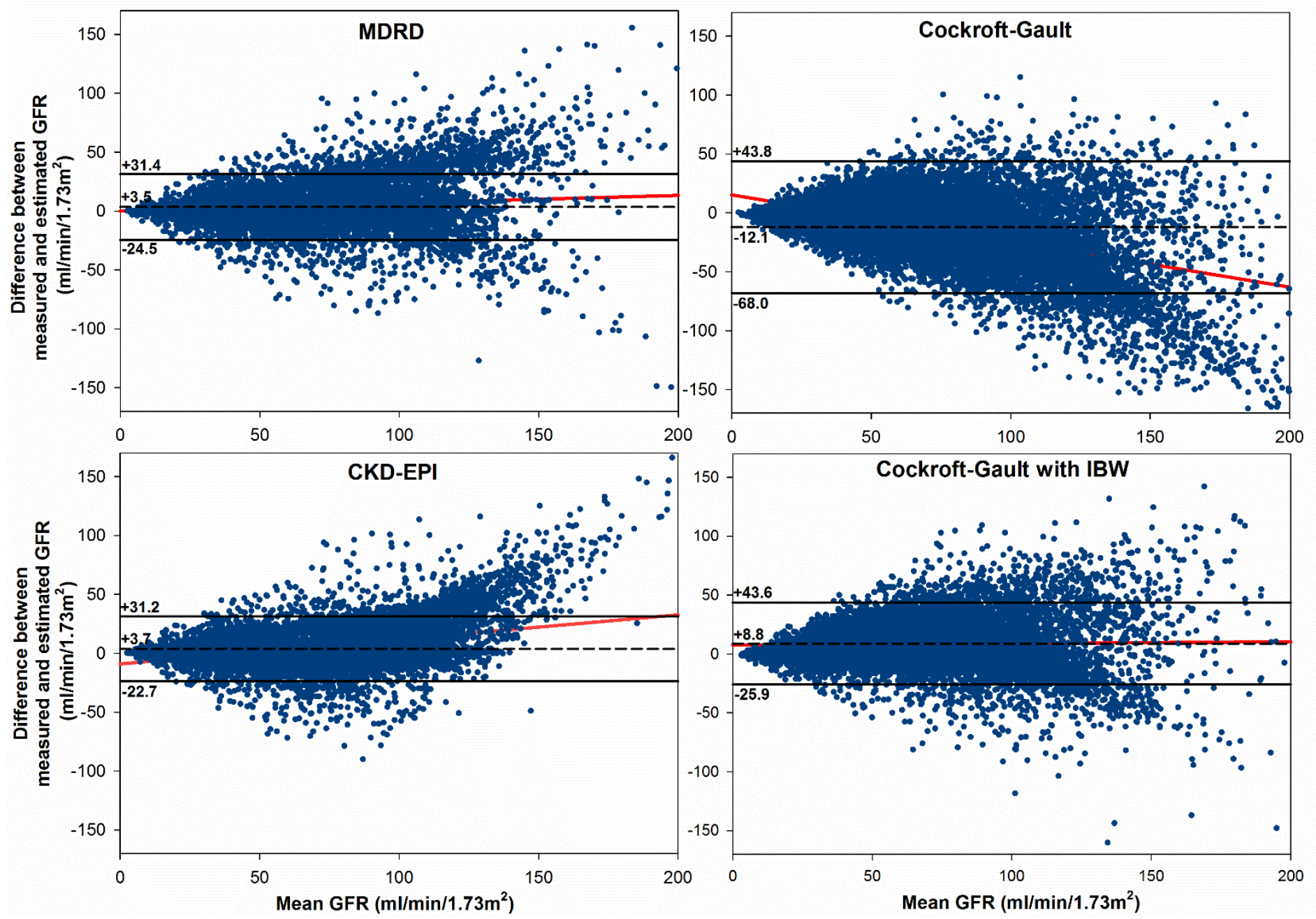
Bland-Altman plots of the estimated and measured renal function for each estimation method. Differences between mGFR and eGFR are plotted against mean GFR values. The dashed lines represent the mean difference, the solid lines depict the lines of agreement calculated as mean difference \pm 1.96 times the SD of this difference.

Abbreviations: glomerular filtration rate (GFR), measured GFR (mGFR), Modification of Diet in Renal Disease (MDRD), Chronic Kidney Disease Epidemiology Collaboration (CKD-EPI), Cockcroft-Gault (CG), CG calculated with ideal body weight (CG-IBW). 
Figure 3
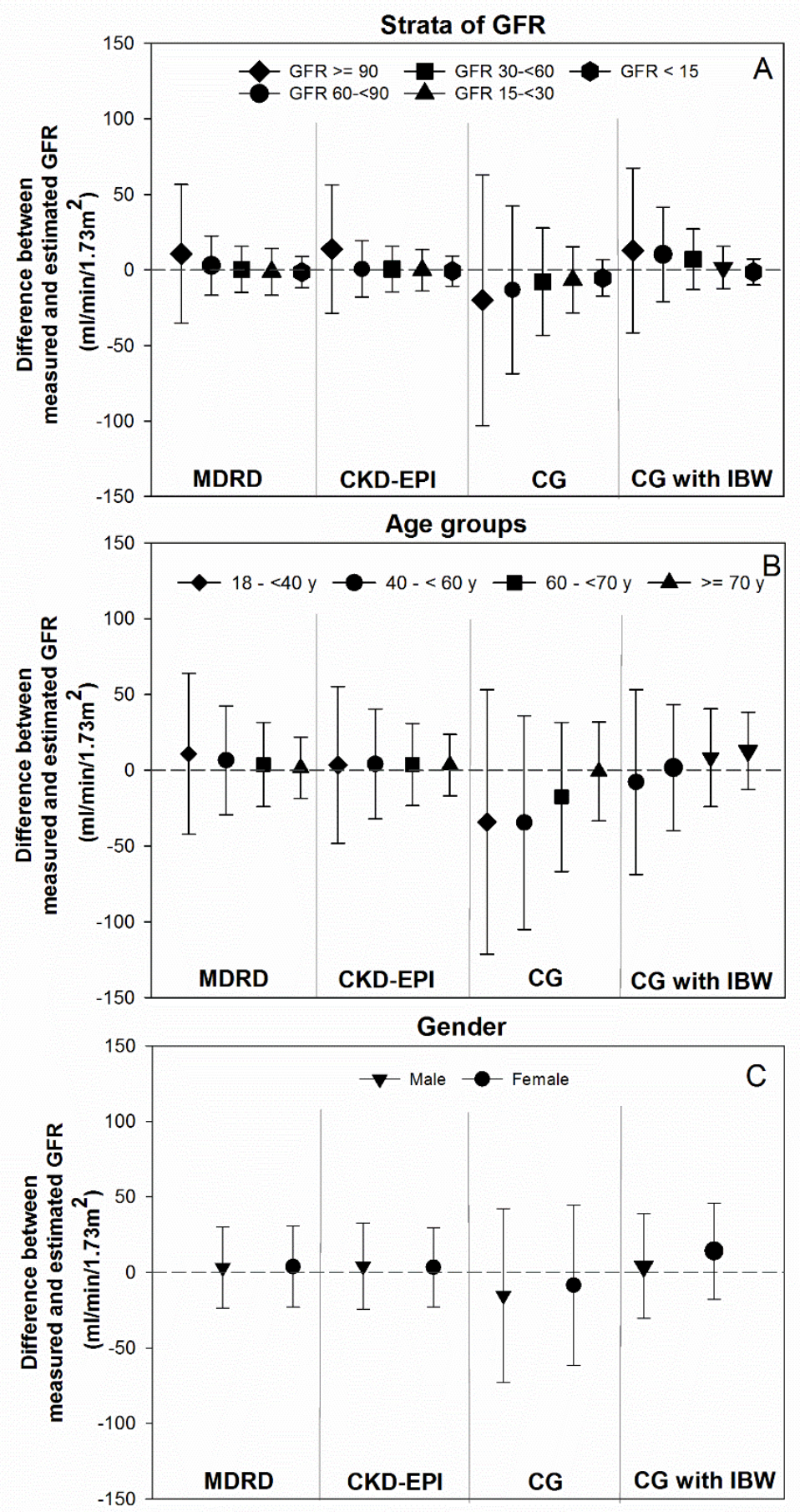

Comparison of mean bias and precisions across subgroups. Mean bias and precision between estimated and measured GFR was calculated separately for stages of CKD, age groups, and gender. 
Abbreviations: chronic kidney disease (CKD), glomerular filtration rate (GFR), Modification of Diet in Renal Disease (MDRD), Chronic Kidney Disease Epidemiology Collaboration (CKD-EPI), Cockcroft-Gault (CG), CG calculated with ideal body weight (CG-IBW). 


\section{Supplement Figure 1}

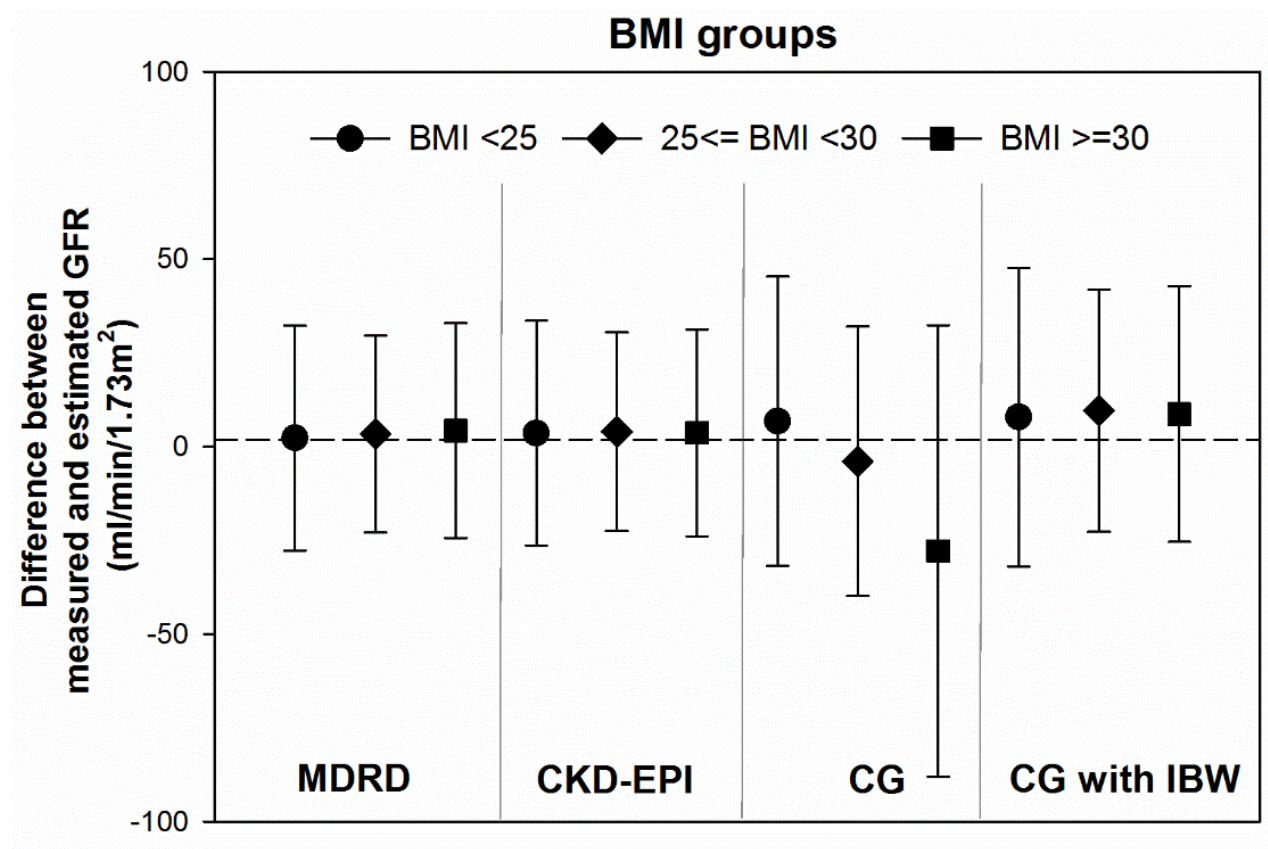

\section{Supplement Figure 1}

Comparison of mean bias and precisions across BMl groups.

Comparison of mean bias and precisions across BMI groups (normal weight $\mathrm{BMI}<25$, overweight $25 \leq \mathrm{BMI}<30$, obese $\mathrm{BMI} \geq 30$ ).

Abbreviations: chronic kidney disease (CKD), glomerular filtration rate (GFR), Modification of Diet in Renal Disease (MDRD), Chronic Kidney Disease Epidemiology Collaboration (CKD-EPI), Cockcroft-Gault (CG), CG calculated with ideal body weight (CG-IBW), Body mass index (BMI). 
Table 1 Definition of estimation methods

\begin{tabular}{|c|c|}
\hline Estimation Method & Equation \\
\hline MDRD & $175 \times$ creatinine $[\mathrm{mg} / \mathrm{dl}]^{-1.154} \times$ age $\left[\right.$ years] ${ }^{-0.203} \times 0.742$ [if female] \\
\hline CKD-EPI & $\begin{array}{l}141 \times \min \{\text { creatinine } / k, 1\}^{\alpha} \times \max \{\text { creatinine } / k, 1\}^{-1.209} \times 0.993^{\text {age }} \text { [years] } \times 1.018 \text { [if female] } \\
\text { where } k \text { is } 0.7 \text { for females and } 0.9 \text { for males, } \alpha \text { is }-0.329 \text { for females and }-0.411 \text { for males }\end{array}$ \\
\hline CG & $((140$ - age $[$ years] $) \times$ body weight $[\mathrm{kg}]) /$ creatinine $[\mu \mathrm{mol} / \mathrm{l}] \times 0.85$ [if female] \\
\hline CG-IBW & $\begin{array}{l}((140 \text { - age }[\text { years }]) \times I B W) / \text { creatinine }[\mu \mathrm{mol} / /] \times 0.85 \text { [if female] } \\
\text { where } I B W=50+0.9 \times(\text { length }[\mathrm{cm}]-152) \text { for males and IBW }=45.5+0.9 \times(\text { length }[\mathrm{cm}]-152) \text { for females }\end{array}$ \\
\hline
\end{tabular}

Equations for estimating renal function based on serum creatinine.

Abbreviations: glomerular filtration rate (GFR), Modification of Diet in Renal Disease (MDRD), Chronic Kidney Disease Epidemiology Collaboration (CKD-EPI), Cockcroft-Gault (CG), ideal body weight (IBW), Cockcroft-Gault with IBW (CG-IBW). 
Table 2 Demographics of the entire study cohort and separated by type of diabetes.

\begin{tabular}{|c|c|c|c|}
\hline & Study population & Type-1-diabetes & Type-2-diabetes \\
\hline $\mathbf{N}$ & 24,516 & 2,222 & 22,294 \\
\hline \multicolumn{4}{|l|}{ Demographics } \\
\hline Male (\%) & 52.5 & 55.1 & 52.3 \\
\hline Age (years) & $72.0[61.0 ; 79.2]$ & $48.2[31.0 ; 62.0]$ & $73.1[63.5 ; 79.8]$ \\
\hline Duration of diabetes (years) & $9.9[4.2 ; 16.0]$ & $15.8[7.6 ; 29.0]$ & $9.7[4.0 ; 15.4]$ \\
\hline $\mathrm{HbA1c}(\mathrm{mmol} / \mathrm{mol})$ & $54.9[45.8 ; 69.2]$ & $60.1[50.4 ; 77.1]$ & $54.2[45.4 ; 68.1]$ \\
\hline BMI $\left(\mathrm{kg} / \mathrm{m}^{2}\right)$ & $29.2[25.6 ; 33.6]$ & $24.7[22.3 ; 28.2]$ & $29.6[26.1 ; 34.0]$ \\
\hline $\operatorname{BSA}\left(m^{2}\right)$ & $2.0[1.8 ; 2.1]$ & $1.9[1.7 ; 2.0]$ & $2.0[1.8 ; 2.1]$ \\
\hline \multicolumn{4}{|l|}{ Comorbidities } \\
\hline Hypertension, \% & 70.9 & 46.7 & 73.3 \\
\hline Microalbuminuria, \% & 39.6 & 31.4 & 40.5 \\
\hline Treatment with ACE inhibitors, \% & 15.6 & 8.1 & 15.2 \\
\hline Smoking, \% & 7.6 & 14.0 & 7.0 \\
\hline \multicolumn{4}{|l|}{ Kidney function } \\
\hline Creatinine (mg/dl) & $1.1[0.8 ; 1.4]$ & $0.9[0.8 ; 1.1]$ & $1.1[0.9 ; 1.5]$ \\
\hline Creatinine ( $\mu \mathrm{mol} / \mathrm{l})$ & $93.7[73.4 ; 126.4]$ & $79.6[66.3 ; 97.2]$ & $96.4[75.0 ; 130.0]$ \\
\hline Measured GFR (ml/min/1.73m²) & $\begin{array}{c}63.0[43.1 ; 88.0] \\
67.3 \pm 32.7\end{array}$ & $\begin{array}{c}90.9[64.0 ; 113.0] \\
90.0 \pm 37.3\end{array}$ & $\begin{array}{c}60.8[42.0 ; 85.0] \\
65.1 \pm 31.3\end{array}$ \\
\hline Estimated GFR & & & \\
\hline
\end{tabular}




\begin{tabular}{l|c|c|c} 
MDRD $\left(\mathrm{ml} / \mathrm{min} / 1.73 \mathrm{~m}^{2}\right)$ & $60.7[42.2 ; 82.6]$ & $84.0[62.4 ; 102.0]$ & $58.6[41.0 ; 80.0]$ \\
& $63.9 \pm 29.7$ & $82.8 \pm 32.4$ & $62.0 \pm 28.7$ \\
CKD-EPI $\left(\mathrm{ml} / \mathrm{min} / 1.73 \mathrm{~m}^{2}\right)$ & $61.9[41.5 ; 86.1]$ & $92.0[66.4 ; 108.9]$ & $59.1[40.3 ; 83.1]$ \\
& $63.6 \pm 27.9$ & $86.6 \pm 30.5$ & $61.3 \pm 26.5$ \\
CG $(\mathrm{ml} / \mathrm{min})$ & $69.2[45.4 ; 104.5]$ & $100.5[68.7 ; 131.1]$ & $66.8[44.3 ; 100.4]$ \\
& $79.4 \pm 45.8$ & $101.8 \pm 45.3$ & $77.2 \pm 45.2$ \\
CG-IBW $(\mathrm{ml} / \mathrm{min})$ & $52.2[34.7 ; 77.6]$ & $89.0[59.5 ; 116.7]$ & $49.8[33.7 ; 73.0]$ \\
& $59.0 \pm 32.4$ & $90.1 \pm 40.1$ & $55.9 \pm 29.7$ \\
\hline
\end{tabular}

Results are given as median with quartiles for continuous variables and as proportions for binary variables. Measured and estimated GFR are additionally presented as mean \pm SD.

Abbreviations: hemoglobin A1c (HbA1c), body mass index (BMI), body surface area (BSA), glomerular filtration rate (GFR), Modification of Diet in Renal Disease (MDRD), Chronic Kidney Disease Epidemiology Collaboration (CKD-EPI), Cockcroft-Gault (CG), CG calculated with ideal body weight (CG-IBW). 
Table 3 Accuracy (\%) for each estimation method.

\begin{tabular}{|c|c|c|c|c|}
\hline & MDRD & CKD-EPI & CG & CG-IBW \\
\hline Entire study cohort & 75.3 & 70.4 & 27.2 & 30.5 \\
\hline \multicolumn{5}{|l|}{ Strata of GFR } \\
\hline GFR $\geq 90 \mathrm{ml} / \mathrm{min} / 1.73 \mathrm{~m}^{2}$ & 57.8 & 57.3 & 24.4 & 33.5 \\
\hline GFR $60-<90 \mathrm{ml} / \mathrm{min} / 1.73 \mathrm{~m}^{2}$ & 80.2 & 80.7 & 28.6 & 29.2 \\
\hline GFR $30-<60 \mathrm{ml} / \mathrm{min} / 1.73 \mathrm{~m}^{2}$ & 82.3 & 74.0 & 28.9 & 28.2 \\
\hline GFR $15-<30 \mathrm{ml} / \mathrm{min} / 1.73 \mathrm{~m}^{2}$ & 77.8 & 60.1 & 25.4 & 35.4 \\
\hline GFR $<15 \mathrm{ml} / \mathrm{min} / 1.73 \mathrm{~m}^{2}$ & 71.0 & 49.8 & 14.4 & 35.6 \\
\hline \multicolumn{5}{|l|}{ Age groups } \\
\hline $18-<40$ years & 50.3 & 63.7 & 19.7 & 34.6 \\
\hline $40-<60$ years & 68.7 & 72.8 & 16.3 & 44.2 \\
\hline $60-<70$ years & 77.3 & 75.7 & 22.9 & 42.1 \\
\hline$\geq 70$ years & 78.9 & 68.1 & 33.1 & 21.2 \\
\hline \multicolumn{5}{|l|}{ Gender } \\
\hline Male & 75.3 & 69.6 & 27.3 & 40.3 \\
\hline Female & 75.3 & 71.2 & 27.1 & 19.5 \\
\hline \multicolumn{5}{|l|}{ BMI groups } \\
\hline $\mathrm{BMI}<25$ & 72.6 & 66.0 & 29.7 & 25.3 \\
\hline $25 \leq \mathrm{BMI}<30$ & 76.0 & 69.1 & 40.2 & 27.3 \\
\hline $\mathrm{BMI} \geq 30$ & 75.6 & 72.9 & 15.6 & 29.8 \\
\hline \multicolumn{5}{|l|}{ Hypertension } \\
\hline Yes & 74.8 & 68.9 & 27.4 & 28.6 \\
\hline No & 76.4 & 73.8 & 26.6 & 34.7 \\
\hline \multicolumn{5}{|l|}{ Microalbuminuria } \\
\hline Yes & 70.8 & 62.6 & 26.0 & 26.0 \\
\hline No & 74.8 & 71.4 & 28.3 & 30.5 \\
\hline
\end{tabular}


Comparison of accuracy (proportion of eGFR within $\pm 10 \%$ of $m$ GFR values) across subgroups of stages of CKD, age groups, gender, and BMI groups. Values in bold depict highest accuracy compared to the other formulas (all $p<0.01$ ).

Abbreviations: glomerular filtration rate (GFR), Modification of Diet in Renal Disease (MDRD), Chronic Kidney Disease Epidemiology Collaboration (CKD-EPI), Cockcroft-Gault (CG), CG calculated with ideal body weight (CG-IBW), Body mass index (BMI). 